\title{
Hydroxyapatite coating by biomimetic method on titanium alloy using concentrated SBF
}

\author{
S BHARATI, M K SINHA and D BASU* \\ Bio-ceramics and Coating Division, Central Glass and Ceramic Research Institute, Kolkata 700032 , India
}

MS received 9 March 2005; revised 1 June 2005

\begin{abstract}
This article reports a biomimetic approach for coating hydroxyapatite on titanium alloy at ambient temperature. In the present study, coating was obtained by soaking the substrate in a 5 times concentrated simulated body fluid (5XSBF) solution for different periods of time with and without the use of $\mathrm{CaO}_{-} \mathrm{SiO}_{2}$ based glass as a possible source of nucleating agent of apatite formation. Optical microscopic and SEM observations revealed the deposition of $\mathrm{Ca}-\mathrm{P}$ layer on the titanium alloy by both the methods. Thickness of coating was found to increase with the increase in immersion time. The use of glass did not help the formation of apatite nuclei on the substrate and the coating obtained by this method was also not uniform. EDX analysis indicated that the coating consisted of Ca-P based apatite globules, mostly in agglomerated form, and its crystallinity was poor as revealed by XRD.
\end{abstract}

Keywords. Biomimetic; apatite; simulated body fluid.

\section{Introduction}

Titanium and some of its alloy (Ti-6Al-4V) are widely used as orthopaedic and dental implant materials due to their low elastic modulus, good biocompatibility and corrosion durability. However, bone does not bond directly to these materials as they get encapsulated by fibrous tissue after implantation, which isolates them from the surrounding bone (Yan and Davies 1998; Nishiguchi et al 1999). Recently, it has been observed that a bioactive titanium surface can be prepared by simple chemical treatment (Sittig et al 1999; Liu et al 2002; Muller et al 2002). In order to enhance the bone-bonding ability, titanium and its alloys are often coated with hydroxyapatite (HAp) by various methods (de Groot et al 1987; Luo et al 1999; Inagaki et al 2003; Yan et al 2003; Kim et al 2004). Although HAp coating by plasma spraying is a well accepted and widely used technique, it has some intrinsic drawbacks related to the extremely high processing temperature. Coating of intricate shapes as well as incorporation of growth factors that stimulate bone healing are impossible by this coating technique. Moreover, this process cannot provide uniform coatings on porous metal surfaces (Duchyene et al 1986; Thomas et al 1987) and often closes the minute but essential surface features. Recent research has shown that the biomimetic process is one of the most promising techniques for producing a bioactive coating at ambient temperature (Costa and Maquis 1998; Kokubo et al 1999; Varma et al 1999; Hata

\footnotetext{
*Author for correspondence (dbasu@cgcri.res.in)
}

et al 2001; Li et al 2002), overcoming the drawbacks of plasma-spraying. This is a method in which a biologically active apatite layer is formed on a substrate after immersion in an artificially prepared supersaturated calcium and phosphate solution known as simulated body fluid (SBF). The process is based on the heterogeneous nucleation of calcium phosphate from SBF which is supersaturated towards HAp at $\mathrm{pH}=7.4$ and temperature, $37^{\circ} \mathrm{C}$. The classical biomimetic $\mathrm{Ca}-\mathrm{P}$ coating normally requires an immersion period of about 14-28 days with replenishment of SBF solution. In very recent years efforts have been made (Habibovic et al 2002; Ma et al 2003; Barrere et al 2004; Muller et al 2004) to make this process fast to increase its practical utility.

In the present study, attempts have been made to develop a biomimetic $\mathrm{Ca}-\mathrm{P}$ coating on titanium alloy substrates by immersing them into concentrated SBF (5XSBF) with and without using a $\mathrm{CaO}-\mathrm{SiO}_{2}$ based glass as a source of nucleating agent for apatite formation on the surface.

\section{Materials and methods}

\subsection{Preparation of glass}

A glass of nominal composition of $\mathrm{MgO} 4 \cdot 6, \mathrm{CaO} 44 \cdot 7$, $\mathrm{SiO}_{2} 34 \cdot 0, \mathrm{P}_{2} \mathrm{O}_{5} 16 \cdot 2$ and $\mathrm{CaF}_{2} 0.5 \mathrm{wt} \%$ was chosen as the $\mathrm{CaO}-\mathrm{SiO}_{2}$-based source of nucleating agent for apatite. $\mathrm{A}$ powder mixture of the chemical reagents of $\mathrm{CaCO}_{3}, \mathrm{SiO}_{2}$, $\mathrm{CaHPO}_{4} \cdot 2 \mathrm{H}_{2} \mathrm{O}, \mathrm{MgO}$ and $\mathrm{CaF}_{2}$ was melted in a Pt crucible at $1450^{\circ} \mathrm{C}$ for $2 \mathrm{~h}$ in an electric furnace with $\mathrm{MoSi}_{2}$ heating elements. The glass obtained after quenching was 
crushed by an agate mortar and sieved to obtain grains of $150-300 \mu \mathrm{m}$ in size.

\subsection{Preparation of $S B F$ and $5 X S B F$}

SBF is known to be a metastable buffer solution and even a small variance in both of the preparation step and storage temperature may drastically affect the kinetics and phase purity of the biomimetic coating. SBF solution was prepared by dissolving appropriate quantities of reagent grade $\mathrm{NaCl}, \mathrm{NaHCO}_{3}, \mathrm{KCl}, \mathrm{Na}_{2} \mathrm{HPO}_{4} \cdot 2 \mathrm{H}_{2} \mathrm{O}, \mathrm{MgCl}_{2} \cdot 6 \mathrm{H}_{2} \mathrm{O}$, $\mathrm{CaCl}_{2} \cdot 2 \mathrm{H}_{2} \mathrm{O}, \mathrm{Na}_{2} \mathrm{SO}_{4}$ and TRIS buffer into double distilled water (Tas 2000). $1 \mathrm{M} \mathrm{HCl}$ was used to maintain $\mathrm{pH}$ of the solution at 7.4 at $37^{\circ} \mathrm{C}$.

$5 \mathrm{XSBF}$ solution with ion concentrations of 5 times those of SBF (table 1) was prepared from reagent grade $\mathrm{NaCl}$, $\mathrm{NaHCO}_{3}, \mathrm{Na}_{2} \mathrm{HPO}_{4} \cdot 2 \mathrm{H}_{2} \mathrm{O}, \mathrm{MgCl}_{2} \cdot 6 \mathrm{H}_{2} \mathrm{O}$ and $\mathrm{CaCl}_{2} \cdot 2 \mathrm{H}_{2} \mathrm{O}$ chemicals dissolved in double distilled water and $\mathrm{pH}$ of the solution was maintained at 6 using $1 \mathrm{M} \mathrm{HCl}$.

\subsection{Sample preparation}

Titanium alloy (Ti-6Al-4V) rods of size $4 \mathrm{~mm} \phi \times 4 \mathrm{~mm}$ length were roughened mechanically using emery paper (size, 36; Eastern Abrasive Ltd., India) to obtain an average roughness, $R a=1 \mu \mathrm{m}$. The samples were then cleaned ultrasonically in acetone, ethanol and distilled water and dried in air.

\subsection{Biomimetic coating process}

Two methods were followed to study the deposition of bioactive material on the mechanically roughened surfaces of Ti-6Al-4V. In method I, a two-step soaking procedure was followed. In the first step, the metallic sample (marked as sample-I) was placed on glass particles and soaked in SBF at $37^{\circ} \mathrm{C}$ in a glass container for 6 days. The sample was immersed thereafter in 5XSBF for 10 days (figure 1). In method II, the Ti-6Al-4V sample (marked as sample-II) was directly immersed in 5XSBF solution at $37^{\circ} \mathrm{C}$ and examined at different intervals of time up to 13 days.

\subsection{Characterization}

The coating formed was characterized using a Vicker's optical microscope and image analyser (Model Leica Q500 MC), X-ray diffractometer (XRD: Model Phillips Analytical PW1710, Holland), scanning electron microscope (SEM: Model LEO 430i STEROSCAN, UK) and energy dispersive X-ray analysis (EDX).

\section{Results and discussion}

It was observed that the $\mathrm{pH}$ of $5 \mathrm{XSBF}$ solutions increased from 6 before immersion to $6 \cdot 3$ after 10 days of immersion in method I and to 6.7 after 13 days in method II.

Table 1. Inorganic composition of human blood plasma (HBP), simulated body fluid (SBF) and $5 \mathrm{XSBF}$.

\begin{tabular}{lcccccccc}
\hline & \multicolumn{7}{c}{ Ion concentration (mM) } \\
\cline { 2 - 8 } Component & $\mathrm{Na}^{+}$ & $\mathrm{K}^{+}$ & $\mathrm{Ca}^{2+}$ & $\mathrm{Mg}^{2+}$ & $\mathrm{Cl}^{-}$ & $\mathrm{HPO}_{4}^{2-}$ & $\mathrm{HCO}_{3}^{-}$ & $\mathrm{SO}_{4}^{2-}$ \\
\hline HBP & $142 \cdot 0$ & $5 \cdot 0$ & $2 \cdot 5$ & $1 \cdot 5$ & $103 \cdot 0$ & $1 \cdot 0$ & $27 \cdot 0$ & $0 \cdot 5$ \\
SBF & $142 \cdot 0$ & $5 \cdot 0$ & $2 \cdot 5$ & $1 \cdot 5$ & $147 \cdot 8$ & $1 \cdot 0$ & $4 \cdot 2$ & $0 \cdot 5$ \\
5XSBF & $714 \cdot 8$ & - & $12 \cdot 5$ & $7 \cdot 5$ & $723 \cdot 8$ & 5 & 21 & - \\
\hline
\end{tabular}

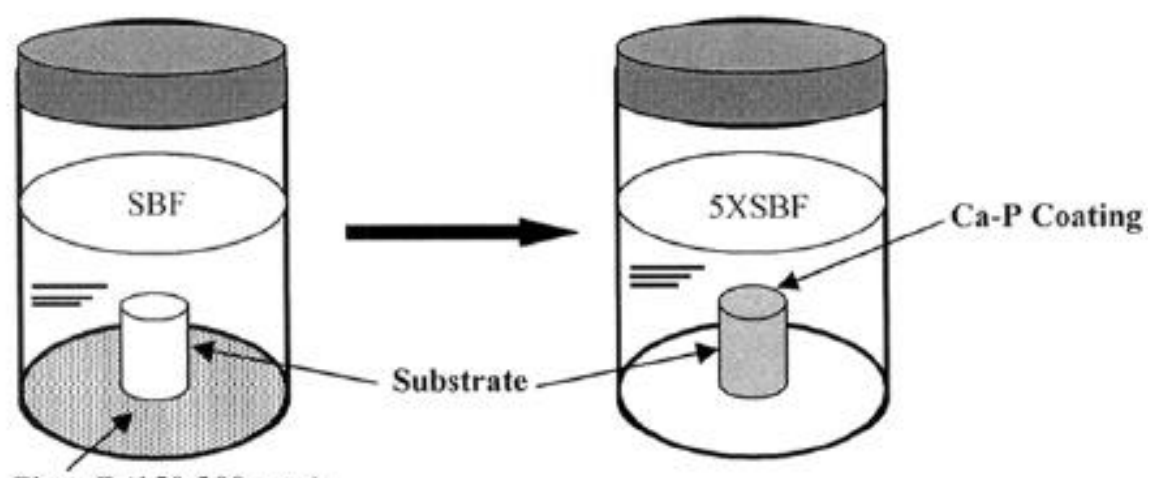

Glass G (150-300 $\mu \mathrm{ms})$

Nucleation of Ca-P Coating

Growth of Ca-P Coating

Figure 1. Basic process of biomimetic coating using bioactive glass powder. 

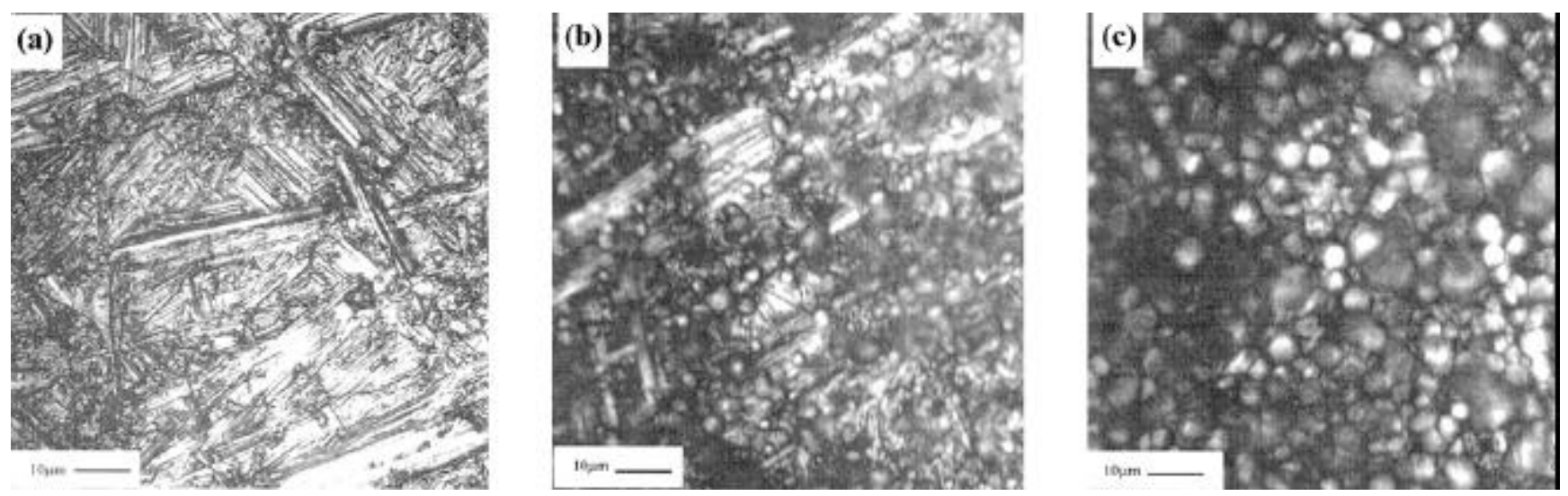

Figure 2. Optical microscopic pictures of (a) uncoated substrate, (b) coated sample-I and (c) coated sample-II after immersion in $5 \mathrm{XSBF}$.
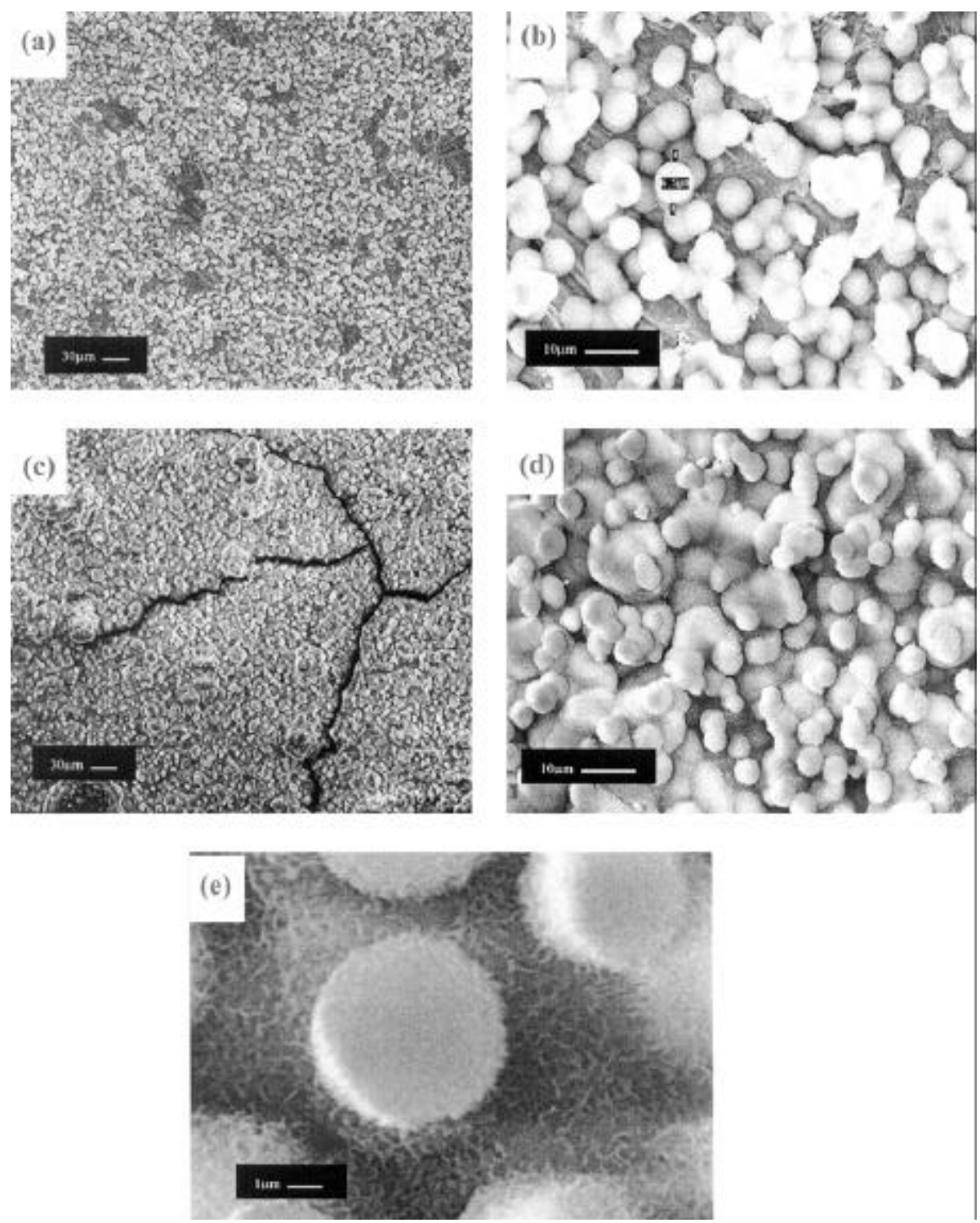

Figure 3. SEM micrographs of sample-I at (a) lower magnification, (b) higher magnification and sample-II at (c) lower magnification, (d) higher magnification, (e) single particle after immersion in 5XSBF. 
While the $\mathrm{pH}$ increased, 5XSBF solution gradually reached supersaturation and thereafter the labile state at which a thin layer of $\mathrm{Ca}-\mathrm{P}$ coating was formed on the substrates.

Figure 2 shows the optical micrographs of the samples without and with apatite coating at $400 \times$ magnification. Prior to immersion in the solutions, numerous deep scratches due to mechanical polishing were visible on the surfaces (figure 2a). No change in weight was observed in case of sample-I even after 6 days of immersion in SBF containing glass particles which indicates that nucleation was not triggered by these nucleating agents on the metal substrate. In the second step, when the sample was immersed in 5XSBF, a slight increase in weight $\left(0.6 \mathrm{mg} / \mathrm{cm}^{2}\right)$ was observed and a thin layer of coating was visible (figure $2 b$ ) after 10 days of immersion. In method II, there was no change in weight after 3 days of soaking in 5XSBF. However, after 6 days, there was slight increase in weight and a very thin layer of coating was visible on the surface. Some precipitation had also taken place in 5XSBF solution. Hence the solution was changed and the sample was soaked again for a further 7 days. After a total of 13 days of immersion, the weight gain in this case was found to be $1.6 \mathrm{mg} / \mathrm{cm}^{2}$. The sample was observed using an optical microscope to check the nature and morphology of the coating (figure 2c).

SEM of sample-I at low magnification (figure 3a) revealed the presence of a $\mathrm{Ca}-\mathrm{P}$ coating on the metallic surface. It was further observed that the coating was not uniform and at a few places uncoated metallic parts were visible. When examined at higher magnification (figure $3 b$ ), spheroid globules, mostly in agglomerated form were clearly observed with the size of the individual globules ranging from 4-7 $\mu \mathrm{m}$. However, SEM of the coating obtained in method II (figure 3c) revealed that a uniform layer of $\mathrm{Ca}-\mathrm{P}$ had been deposited all over the surface. Some distinct cracks were seen in the coating, these had probably formed during the drying process. The coating was found to consist of globules in the range of 2-8 $\mu \mathrm{m}$ in this case also (figures $3 \mathrm{c}-\mathrm{d}$ ). The examination of an individual globule at further higher magnification (figure 3e) exhibited nanometric nuclei indicating that HAp was poorly crystallized.

EDX analysis of both the coatings (figure 4) showed the presence of $\mathrm{Ca}, \mathrm{P}, \mathrm{O}$ as well as $\mathrm{Na}, \mathrm{Mg}, \mathrm{Cl}$ and $\mathrm{C}$. The major peaks due to $\mathrm{Ca}, \mathrm{P}$ and $\mathrm{O}$ indicated that the coating composed of $\mathrm{Ca}-\mathrm{P}$ phase. The $\mathrm{C}$ peak might have originated from the carbon coating that is required for sample preparation. The analysis also revealed that $\mathrm{Mg}$ and $\mathrm{Na}$ got incorporated in the $\mathrm{Ca}-\mathrm{P}$ apatitic coating. A minor peak of Ti due to the substrate was present in case of sample-I (figure 4a) which indicates that the coating was not thick enough to prevent the penetration of X-ray beam up to the substrate surface, whereas the absence of this peak in sample-II (figure $4 \mathrm{~b}$ ) provided an indirect evidence that the coating in this case was thicker and more continuous than that obtained by method I.

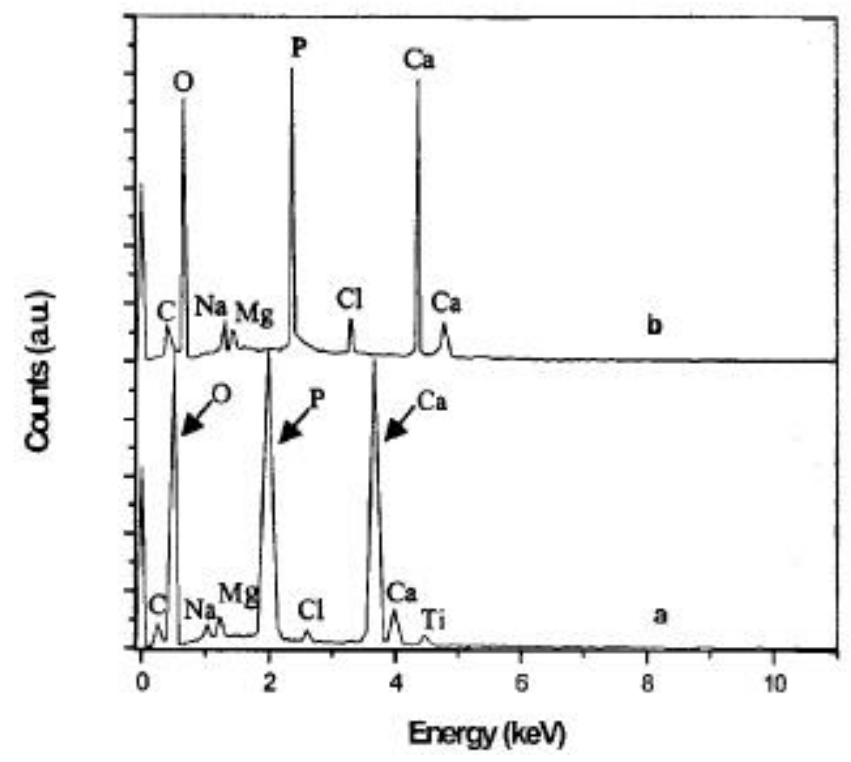

Figure 4. EDX spectra of (a) sample-I and (b) sample-II after immersion in 5XSBF.

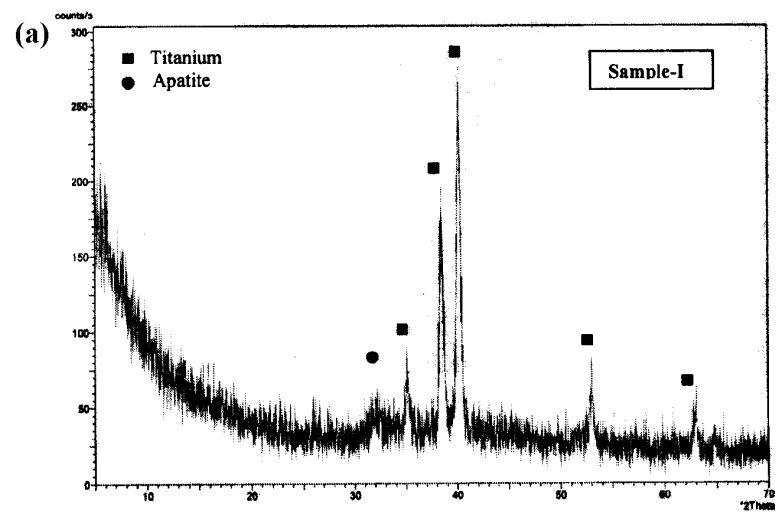

(b)

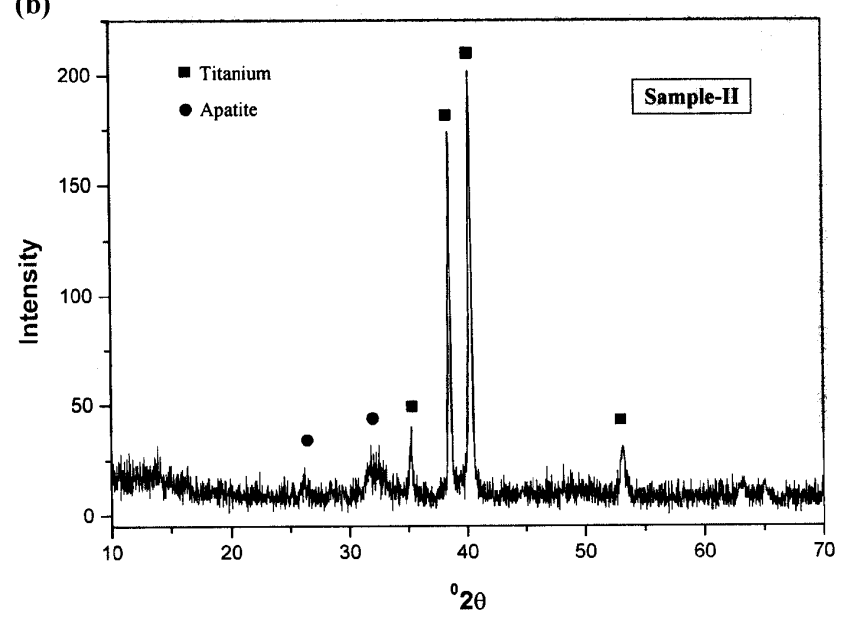

Figure 5. XRD spectra of the coating after immersion in 5XSBF: (a) sample-I and (b) sample-II. 
Figure 5 shows the XRD spectra of the coatings obtained by both the methods. XRD of sample-I exhibited major peaks of titanium alloy along with a slight bump at $2 \theta \sim 32^{\circ}$ (figure 5a). This bump was characteristic of the apatite diffraction line indicating an amorphous or very poorly crystallized structure. However, in case of sampleII, slightly broad diffraction lines at about $2 \theta \sim 26 \cdot 1^{\circ}$ and $2 \theta \sim 31.8^{\circ}$ were observed which indicated an apatitic structure (figure $5 b$ ).

\section{Conclusions}

From this study it is concluded that although $\mathrm{CaO}-\mathrm{SiO}_{2}$ based glass is used as a nucleating agent for apatite, in this case, however, the apatite nuclei did not form on the metallic substrate when the sample was placed on the glass particles soaked in SBF at $37^{\circ} \mathrm{C}$ for 6 days. After subsequent soaking in $5 \mathrm{XSBF}$ for 10 days, though HAp was deposited but the coating was not uniform and bare metal part was visible. The coating obtained by immersing the substrate directly in 5XSBF solution was uniform, relatively thick and covered whole surface of the substrate. Further, coating developed by both the methods were found to be poorly crystallized.

\section{Acknowledgements}

We thank Dr S Dutta for discussions and suggestions; $\mathrm{Mr}$ D K Naskar and Mr Sukumar Mondal for technical support; Dr Anup Mukherjee for optical microscope; $\mathrm{Mr}$ Ashok Mondal for SEM and EDX; and Mr Nirmal Ghosh for XRD.

\section{References}

Barrere F, Snel M M E, van Blitterswijk C A, de Groot K and Layrolle P 2004 Biomaterials 252901
Costa N and Maquis P M 1998 Med. Eng. \& Phys. 20602

de Groot K, Geesink R T, Klein C T and Serekian P 1987 J. Biomed. Mater. Res. 211375

Duchyene P, van Raemdonk W, Heughbaert J C and Heughbaert M 1986 Biomaterials 797

Habibovic P, Barrere F, van Blitterswijk C F, de Groot K and Layrolle P 2002 J. Am. Ceram. Soc. 85517

Hata K, Ozawa N, Kokubo T and Nakamura T 2001 J. Ceram. Soc. Jap. 109461

Inagaki M, Yokogawa Y and Kameyama T 2003 J. Mater. Sci: Mater. Med. 14919

Kim H W, Koh Y H, Li L H, Lee S and Kim H E 2004 Biomaterials 252533

Kokubo T, Miyaji F and Kim H M 1999 J. Am. Ceram. Soc. 79 1127

Li F, Feng Q L, Cui F Z, Li H D and Schuberl H 2002 Surf. \& Coat. Technol. 15488

Liu Q, Ding J, Mante F K, Wunder S L and Baran G R 2002 Biomaterials 233103

Luo Z S, Cui F Z and Li W Z 1999 J. Biomed. Mater. Res. 46 80

Ma J, Huifen W, Kong L B and Peng K W 2003 Nanotechnology 14619

Muller F A, Jonasova L, Helebrant A, Strnad J and Greil P 2002 Biomaterials 233095

Muller F A, Jonasova L, Helebrant A, Strnad J and Greil P 2004 Biomaterials 251187

Nishiguchi S, Nakamura T, Kobayashi M, Miyagi F and Kokubo T 1999 Biomaterials 20491

Sittig C, Textor M and Spencer N D 1999 J. Mater. Sci. Mater. Med. 1035

Tas A C 2000 Biomaterials 211429

Thomas K A, Kay J F, Cook S D and Jarcho M 1987 J. Biomed. Mater. Res. 211395

Varma H K, Yokogawa Y, Espinosa F F, Kawamoto Y, Nishizawa K, Nagata F and Kameyama T 1999 Biomaterials 20 879

Yan W Q and Davies J E 1998 Bioceramics 11659

Yan L, Leng Y and Weng L T 2003 Biomaterials 242585 